\title{
THE PROBLEMS AND POSSIBILITIES OF MOBILITY FOR HOME-BASED ELDERS IN NEW ZEALAND
}

\author{
Juliana Mansvelt \& Theodore E. Zorn
}

\begin{abstract}
Physical mobility can be a means of social and spatial exclusion. Qualitative interviews with 19 home-based elders aged 65-96 about their interactions with a range of public and private service providers show that concepts related to mobility are not dependent on the physical ability to move, but centre on the ways in which people are able to, as part of socio-technical networks, connect with others and make things flow through these connections. These homebased elders, who self-identified as needing assistance to leave home, are able to maintain a flow both within and across the boundaries of home. Highlighting three analytical themes (getting out, letting in and finding a way), we suggest that home-based elders are not inactive or immobile; rather their mobile practices centre on connection rather than corporeal travel. A relational view of mobility as 'connection' which considers the role of non-human entities in enabling and dis-abling forms of mobility consequently assists us to understand the problems and possibilities of being differently mobile.
\end{abstract}

\section{INTRODUCTION}

The ability and opportunity to move is crucial to older adults' health, quality of life, independence and life satisfaction (Mollaoğlu, Tuncay \& Fertelli, 2010; Mollenkopf, Hieber \& Wahl, 2011; Webber, Porter \& Menec, 2010). The New Zealand Ministry of Social Development recognises the role of mobility in ageing actively and facilitating elders' mobility is an important goal of New Zealand's 2001 Positive Ageing Strategy. ${ }^{1}$ New Zealand's Positive Ageing Strategy emphasises improving access, use of public transport and parking concessions, road safety, and concession fares for taxis. Such measures are vitally important because physical immobility can be a means of both social and spatial exclusion (Adey, 2010). However, in emphasising mobile practices which focus on the ability to move and travel outside of home spaces, such policies and prac- 
tices may neglect consideration of the ways in which mobility is experienced within the home and of the ways in which it is expressed outside of movement of the physical body. Our starting premise is that physical mobility can be a means of social and spatial exclusion, but that this need not be so.

This paper examines the experiences of elders ${ }^{2}$ who are unable to leave home independently without difficulty. It endeavours to reflect on the ways in which people in the absence of seemingly 'mobile' bodies are able to interact with a range of organisations and service providers. Informed by geographical gerontology (Wiles, 2005) and insights from social gerontology (Levin, 2009; Davey, 2007), the analysis presented in this paper emphasises the ways in which the social and spatial lives and identities of people, things and places are mutually constituted and entangled. One important way in which this entanglement occurs is through movement, conceptualised here in terms of mobility. Asking home-based elders to reflect on their experiences of interacting with organisations can reveal much about the bodily, personal, social and representational mobilities of this group of older people, but also about the ways in which mobility is itself constituted. Both mobility and motility (one's capacity to be mobile) can be examined by exploring interactions of home-based older people with people and things (in material and de-materialised forms) which comprise socio-technical networks (Latour, 2007). Accordingly, the ability to mobilise flows of information, finances, knowledge, and commodities can be seen as a part of one's mobility, with mobility involving not just the movement of physical bodies but implying a capacity to establish meaningful connections and flows between people and places they inhabit. The examination of home-based elders' experiences revealed that networks of people and things operate both materially and discursively to define and normalise particular ways of being mobile, particularly forms of mobility which are predicated on a lack of bodily or cognitive impairment. As a consequence we argue that the possibilities for a diverse range of older people to do mobility differently are enhanced by an understanding of mobility ${ }^{3}$ as 'more than physical' and 'more than human'.

CONCEPTUALISING MOBILITY: MOVING FROM MOBILE BODIES TO MOBILITY BEYOND THE BODY

Elder mobility is commonly described in functional terms which frame physical movement from one space to another (Schwanen \& Zeigler, 2011), for example as 'the ability to move oneself (e.g. by walking, using assistive devices, or by using transportation) within community environments that expand from one's home, to the neighbourhood, and regions beyond' (Webber, Porter \& 
Menec, 2010:443). It is generally accepted that despite the heterogeneity of older people and life situations that, as people age, mobility declines. Agerelated decline in mobility is associated with a number of factors. These include cognitive, psycho-social and physical conditions and increased physical impairment, reduced levels of social participation, changing social/physical/ emotional needs, and financial and environmental factors such as a reduced ability to use and access transport and unsuitable built environments (Metz, 2000). Studies of in-home mobility for elders have focussed on physical functionality and measures of people's ability to undertake basic activities of daily living (ADL) (Katz, 1983). Out-of-home mobility research has often focussed on overcoming the difficulties faced by elders in moving through 'life-spaces', particularly through neighbourhoods and communities and rural and urban areas (Ayis, Bowling, Gooberman-Hill \& Ebrahim 2007; Banister \& Bowling, 2004; Metz, 2000; Rowles, 1983; Stalvey, Owsley, Sloane, \& Ball, 1999). Patla and Shumway-Cook's (1999) mobility continuum, for example, frames mobility as an expanding sphere of movement through space which begins from the room where one sleeps, to the home and extending beyond the boundaries of home space through outdoor, neighbourhood, service community and wider world spaces.

Recent research on older people's preferences highlights that it is both potential and actual ability to be mobile which is significant, noting it is critical for elders to be able to get to places they want or need to go (Mollenkopf, Hieber $\&$ Wahl, 2011). Thus much research on the practical and policy implications of elder mobilities is premised on the complexities of 'getting out' and leaving 'home-space.' Davey's (2007) work, for example, on coping without a car demonstrates the challenges faced by older New Zealanders who hold strong preferences for private (personal) transport and for whom access to private transport is an important element in their quality of life. Such work has been invaluable in highlighting the necessity of appropriate material environments and services to promote the health, wellbeing, independence and social integration of older people. As a consequence, practical and policy interventions have been developed in order to assist elders to remain mobile as they age (such as kneeling buses, age-friendly public transport systems, assistive technologies and inclusive built environments).

Scholars have noted that it is not just actual physical movement which is affected by a range of social, structural, cognitive and environmental factors (including socio-economic status), but that social and societal determinants also influence mobility. Discourses of ageing as impairment, decline and dependency may influence mobility and may be reified in built environments 
and social structures (Laws, 1994), highlighting the need to recognise the impacts of, and to challenge 'disabling' discourses, attitudes and structures which may restrict older people's mobility (Oliver, 1990). It is not just actual mobility which might be affected by the aforementioned material and discursive factors, but one's desire and capacity to move. Banister and Bowling (2004), for example, argue choices to travel should be examined, while Metz (2000) suggests that the benefits which individuals derive from mobility (such as the psychological benefits of movement or community involvement) should be considered an intrinsic part of mobility. The experience of mobility is also viewed as important too, with Mollenkopf, Hieber and Wahl (2011) concluding the individual's subjective evaluation of both perceived and experienced mobility matters. Thus a growing acknowledgement of the complex cognitive, social, representational and material attributes of mobility for elders has begun to raise questions about the ways in which mobility itself might be conceptualised.

Work emerging from the new mobilities paradigm in social sciences (Sheller \& Urry, 2006; Urry, 2007) has provoked a closer examination of the role of movement in everyday life reflecting the ways in which not just people, but things, knowledge and information travel across spaces over a variety of scales and times. Informed by relational perspectives, the new mobilities paradigm has encouraged scholars to think about the ways in which relationships between people and places may enable, reflect or be constitutive of mobilities which may be expressed through different practices and across varied kinds of spaces. ${ }^{4}$ For example, it is possible to travel imaginatively to other places through photos and media images, or to travel through virtual spaces through using a computer or other networked device. Accordingly, Cresswell (2010:18) argues that mobility involves 'the fragile entanglement of physical movement, representation and practices', a view of mobility which encompasses the ways in which movement is experienced, conceived and practiced. Zeigler and Schwanen (2011) draw on these ideas to advocate a broader understanding of mobility for elders - a mobility which is not located in the movement or functionality of material bodies through physical space per se, but in the ways in which movement may occur beyond the body through the transference of aspects of the material and imagined self through electronic, social and psychological spaces. Zeigler and Schwanen (2011:763) argue that an important part of mobilities is consequently the 'mobility of the self': 'a will or psychological disposition to connect with the world and others, with people and places beyond oneself, one's household or one's residence'.

While the discipline of anthropology has long emphasised the role of the material culture, a renewed emphasis on the non-human and material things in 
structuring everyday life has been important in other social sciences in recent years (Dant, 2008). Actor-network approaches have also emphasised the role of the material in structuring social life and the blurriness of the boundaries between human and non-human things (which may exist in material or dematerialised forms, e.g. digital data) (Latour, 2007). Within actor-networks humans are decentred, with agency (the power to effect change) arising as not so much as a consequence of human intentionality but as a result of relations which are product of both human and non-human entities (such as landscapes, animals, machines, documents, electronic information flows, communicative systems). Thus it is possible to see practices such as surfing the net, getting money out of the bank, disposing of waste as practices which require 'morethan-human' movement (Whatmore, 2006), and as practices which require the alignment of both human and non-human things for mobility to occur.

Schillmeier's (2007) research on 'spaces of dis/abled calculation' provides a means of connecting new work on mobilities and the significance of nonhuman and material things. In research on the ways in which blind people manage money technologies, Schillmeier (2007) argues that the physical properties or materialities of things as part of socio-technical networks of human and non-human entities can produce immobilities. Using the example of an automated teller machine (ATM), he demonstrates how capacities of the machine as part of a relational network can be simultaneously enabling and disabling of opportunities, costs and practices for money to flow. ATMS are efficient and easy for a majority of people to use, offering a knowable interface with relatively standardised practices producing a reliable, predictable and efficient outcome. However, ease of access to the circulation of cash is predicated on a socio-technical network which fits a normative frame based around the dominance of visual competence. The standardised interactions of ATMs do not readily allow for differing forms of mobility or ablement, and accordingly people who are unable to reach or negotiate the keypad, whose reactions are incorrect or too slow, or who feel vulnerable in using these machines in public spaces may be 'disabled' to make money flow. Thus when things fail, the power and politics at work in maintaining functioning systems can become evident. Consequently when mobile practices that are habitual in everyday life stop (such as reaching, walking, or using the toilet) the taken for granted expression of a previously functioning actor network (the person[s], blood, skin, flesh and cell, neurons, jars, steps, footpaths, toilets) becomes visible, with the different functioning revealing both the capabilities of the material and the imagined, the human and the non-human, and the different consequences of these functionings for the maintenance of everyday life. 
Thus research from both the mobilities and material turn in social science has much to offer a study of elders' mobilities. In the remainder of this paper we endeavour to understand mobilities as 'more than physical' and 'more than human' considering how home-based elders' embodiment, ideas, and knowledges may travel potentially, actually and representationally through a variety of material, communicative and virtual spaces. Thus in emphasising mobility as the ability to move not just bodies but representations, ideas, and things across different spaces, and in considering how mobilities for home based elders are conceived, experienced and shaped in the context of networks of human and non-human relations, our study hopes to shed insight into the ways in which mobile practices related to interactions with organisations are manifest, with a view to formulating practices that enable rather than dis-able forms of mobilities.

\section{OUR RESEARCH: BEGINNINGS AND NEW DEPARTURES}

The research upon which this paper is based was funded by the New Zealand Foundation for Research Science and Technology (FRST). The research team comprised a multi-disciplinary group of scholars led by Professor Ted Zorn. ${ }^{6}$ The research, now entering the final year of a three year programme (October 2009 - October 2012) is intended to explore how older New Zealanders experience engaging with and interacting with a range of organisations. These include a wide range of voluntary, private sector and publically funded groups such as banks, hospitals, retail outlets, service stations, churches and power companies. The researchers intend to ascertain the extent to which prejudicial attitudes, discriminatory practices and stereotypical beliefs can reduce elders' opportunities for participation. The project also aims to achieve change by trialling practices that contribute to positive elder-organisational relationships within organisations and to develop through workshops a set of age-friendly practices. This paper reports on interviews conducted as part of the first phase of the research.

The bulk of the participants for phase one were termed 'active elders ${ }^{77}$ by the research team. The 53 'active elders' completed detailed Observation Logs (OLOGS) about their interactions with organisations and some participated in focus groups about their interactions with organisations over a period of three weeks in 2010. A second group of 'home-based elders' (on which this paper is based) were recruited through advertisements placed in the newsletters of Age Concern Manawatu, the Manawatu Community Trust (a housing trust based in Feilding) and Palmerston North City Council's Home-based Library Service, all of which were publications delivered directly to individuals' homes. 
Nineteen people volunteered to be interviewed from these advertisements. These participants ( 15 female, 4 male) were aged between 65 and 96 and selfidentified as people who 'found it difficult to leave home, except with the assistance of others' (as per the recruitment advertisement). Though the sample group was largely women, many of the issues identified in terms of mobility were expressed in both the women's and men's interviews. Participants lived primarily in Palmerston North (a city of 80,00o located in the lower North Island of New Zealand) and Feilding and its surrounds (a rural service town in the same region). Participants had a range of conditions, including arthritis, diabetes, heart, bladder/bowel conditions, agoraphobia and/or impairments in hearing, eyesight and physical mobility resulting in differing physical, cognitive and social impairments.

Interviews with home-based elders focussed on the type and frequency of interactions elders had with different organisations. There were no restrictions on the types of organisations mentioned by participants, but prompts were given to talk about service/utility providers, retail firms, leisure activities, health organisations, social/volunteer groups, church/religious organisations, and transport-related organisations, as well as financial and insurance organisations. Open-ended questions explored what was involved in these relationships, over what time periods and when and where contact occurred. Participants were encouraged to reflect on the nature of such interactions, considering how they were experienced, the perspectives/positions of the parties involved and efficacy of the different media through which the interactions took place (face-to-face, online, mail, phone, through a third party). Participants were also asked to discuss the characteristics of positive and negative interactions and to recall examples of these, to consider whether and how such interactions might be influenced by ageing and physical impairment. Finally, participants were asked to suggest any practical changes which might assist them in having more productive and pleasurable interactions with organisations. These interviews were subject to descriptive content analysis, producing a picture of the numbers and types of exchanges, and instances of both positive and negative interactions were developed. A thematic or latent content analysis (Babbie, 1998) of the interviews followed, coding the interviews with an emphasis on developing substantive themes which reflect wider meanings of participant talk (Miles \& Huberman, 1994). Participants' discussion around their strategies and tactics for, and experiences of, mobility were noticed and grouped into three analytical themes: 'getting out', 'letting in' and 'finding a way'. Notions of 'getting out' included the self as well as the need to move things (waste, letters, information, money) across home boundaries. 'Letting in' comprised the ways in which elders were able to produce notions of autonomy and power 
over who and what came or flowed into one's home-space. Finally, 'making a way' encompassed the ways in which individuals sought to overcome relative immobilities and to situate themselves as part of socio-technical networks which enabled the successful production of personal, social, representational and material forms of mobility (albeit while recognising that they often 'did' mobility differently to others). Quotes from selected participants (for whom pseudonyms are given) are used to illustrate these key themes.

\section{ON BEING DIFFERENTLY MOBILE - FINDINGS AND INSIGHTS}

The home-based elders' stories were tales of the challenges faced by older people in interacting with a range of in-home and out-of-home service providers and organisations, but also constituted stories of resilience and activity. Many of the home-based elders did have impairments which influenced their physical ability to independently transgress the spatial boundaries of the home in which they lived, but rather than being immobile or inactive they sought through their talk to demonstrate adaptation rather than deficiency, noting ways in which their mobile practices differed from others. Participants strongly resisted notions of idleness, non-productivity and non-contribution which came from a discursive framing of their relatively sedentary bodies. Accordingly, for the researchers the construction of home-based elders as inactive and immobile when compared to the 'active' elder group required re-thinking.

The home-based elders recognised they 'did' mobility differently to others, and many were keen to demonstrate the ways in which they were proactively achieving the kinds of flows and connections with other people and things that they both needed and desired. Participants also talked about the multitude of ways in which they were enabled and disabled to connect with people, services and things in and outside the home. Mobility here was constructed as bodily, representational (involving the imagined and desirable), and as involving the wider social and material relations in which bodies were located. As Ziegler and Schwanen (2011:768) note in their study of mobility and wellbeing in later life, mobility practices (such as walking to the gate to collect mail, or ringing a friend) were often described as a collection of acts involving movement in space (using steps, opening letter boxes, reaching, dialling numbers) and acts which both made and represent that movement (such as getting out, talking on the phone). Our analysis of the transcripts revealed the inseparable relationship between the material worlds people inhabited (the capabilities of their bodies, finances, houses, environments, technologies) and their felt and imagined experiences associated with mobile practices (being independent, happy, connected, lonely, ignored), confirming that mobility was not simply 
about movement in physical but also cognitive and social space.

Despite the frustrations of being unable to leave home except without assistance, and of the ways in which they felt they were treated at times (varying from being ignored to intentional mistreatment) participants recounted that on the whole their interactions with organisations were positive. Perhaps not surprisingly in the context of this particular research on organisational interactions, mobilities were about establishing spaces and conduits of connection. As a result, many participants talked about the desire to overcome frictions to communicative encounters in order to make bodies, things or ideas flow. Participants recognised their connection with and to 'the world' was not simply a matter of their agency but of the capacities of networks to enable flows of people, knowledge and things which accommodated their differing mobile practices. Thus the presence of steps rather than ramps, a lack of seats in public spaces and shops, a heavy door, an unreachable lock on a toilet, or an unintelligible automated voice became significant in configuring the normativity of participants who endeavoured to interact with these things.

Our interpretations of participant stories revealed the way in which forms of corporeal ablement are privileged in many communicative interactions and the sorts of frictions which slow or even stop the movements of people, information and things. An inability to see well, for example, can negate one's ability to engage in mobile practices through a whole range of communicative means offered by an organisation, including an ability to use the phone, read and respond to mail, use the computer, and visit an organisation's offices. Yet the analysis indicated that even the smallest changes in such networks (braille buttons, a caregiver who will respond to phone messages, large print text) can open up one's world to new mobile possibilities.

That mobilities were laden with power (Cresswell, 2010) was expressed in participant talk. Evident was a frustration in the reluctance of participants' bodies to move, to see, to hear and grasp as they felt it should (and in most cases as it once had). Power was felt in the weight of signification which saw glances and gazes of others which ignored or marginalised their presence and needs, and in the ways political, economic and social systems did not easily account for their differing abilities to move or to make things move. Thus, as Frello (2008) suggests, the distinction between 'here' and 'there' was expressed simultaneously through a range of spaces (physical, mental, representational, social and virtual space). The ability to move imaginatively, virtually and physically was also premised on what Hannam, Sheller and Urry (2006) describe as 'moorings' with fixity in both time and place necessary in order to make corporeal bod- 
ies, information and material things flow (Burnett \& Lucas, 2010). For home based elders, this fixity was often expressed less in terms of the existence of stable entities in place, than with a predictability and stability in the functioning and organisation of networks (such as suitable and known places to rest on a journey, reliable taxi services, disability carparks that were available, a reliable internet connection, a known voice on the end of the phone) in order to achieve mobility of the self. However, balanced alongside needs for predictability and stability was the importance of networks in which individuals could engage flexibly (for example by using other than face-to-face or phone communication).

In order to extend these themes, we focus now on three constructs of the ways in which mobility is shaped through participant transcripts: 'getting out', 'letting in' and 'finding a way'. All three themes draw on spatial metaphors which have both material and representational expressions and all operate to some extent in relation to boundaries - in the first two, the home boundary, and in the case of 'finding a way', across boundaries of various scales from the divisions between rooms within a house to negotiating hierarchal spaces of an organisation.

\section{GETTING OUT:}

In line with more traditional notions of mobility, a number of elders expressed their desire to 'get out' in terms of being able to travel outside their home. Alice, who was in a wheelchair and had extremely limited mobility in her arms, legs and hands because of arthritis, suggests even just seeing a few gypsy caravans provides a chance to experience life outside the home:

And then I have friends who take me, like we went through all the gypsy caravans on Saturday. They're nothing, but it's an outing. (Alice, 79)

She noted how her life 'outside' has become dependent on her caregiver, but in the absence of someone to take her out, it was flows of friends who called in which she noted 'keep her going', giving her a sense of connectedness to the 'outside' world:

Arthritis, yeah. I used to have more (contact with the Arthritis Association) but since I have been ill this last year I've had to, I can't go out without a caregiver you know. That really ties you down, yeah really but otherwise I've got lots of friends and you know yes, yes, that keeps me going, yeah. (Alice, 79) 
A dependence on others, particularly paid caregivers to maintain physical mobility outside the home, was common. A number of participants expressed a reluctance to call on neighbours, friends or family for other than essential trips to town or to the doctor. Thus getting out was often weighed up in relation to need (that which was deemed necessary) versus desire (that which would simply be nice), with the latter often occurring in the context of the elder not wanting to be a burden, and in the context of the 'busy lives' and demands of others. Dale, for example, describes her reluctance to ask her children, despite their willingness to assist:

Well I'm fortunate because I've got three children in Palmerston North but they all work full time.... They always say 'Now, mum, you have only got to ask!' but when you have got to my stage and you know they're jolly busy, they've all got children at home and when they are working full time you don't always like to. (Dale, 75$)$

Consequently for a number of participants, 'outings' tended to be dominated by visits to organisations: doctors, chemists, supermarkets, and banks, for what participants saw as pragmatic rather than social reasons. Perhaps because of this, many home-based elders stressed the importance of and the desire for pleasurable social exchanges in these encounters.

Moving one's body outside of the home also depended on the real and imagined nature of material environments and things. For example, for Dale, a large shopping mall in Palmerston North became a space of fear and the unknown, a space of vulnerability. Her description of the slippery shiny tiled floors, wide open spaces, glass and mirrors produced this place as disorienting and disempowering:

The Plaza just makes me feel awful to think about it ... yes but I would never go there on my own. It's overpowering. (Dale, 75)

Similarly, Barbara notes how she does not try to visit her friend in hospital because she knows when she gets there she cannot use the elevator buttons:

She gets to hospital, I can't go and visit because I can't use the lift, can't see the button. (Barbara, 85)

Thus moving bodies outside of home-space was often dependent on the real and imagined consequences of the failure of components of socio-technical networks. Many noted, for example, that it was no use leaving home if they 
were unable to park close to their intended destination, or if they could not manage a step into their preferred shop, or if they could not find and negotiate public toilets.

The thematic analysis revealed how 'getting out' did not just extend to the movement of their own bodies, but the ways in which they sought to move non-human things: letters, cheques, waste, and information across the boundaries of the home. For a number of participants, disposing of rubbish was difficult; many could not lift bags, nor could they push wheelie bins out to the gate. Faith notes, for example, her reliance on others not just to take her out of the house for shopping but to enable her to dispose of her waste.

No, my son he takes my rubbish ... I just sort of put it in the door and he collects that.... My helper who takes me shopping, she showers me three mornings a week.... And she always empties my compost, too. (Faith, 96)

Others talked about the challenges of managing phone banking when they could not see or hear well, or of getting mail posted and bills paid. However, despite the physical challenges they faced, many of the participants spoke about the tactics they had developed to overcome frictions of mobility (primarily through achieving connections beyond their physical bodies by enrolling other people and things in their mobile practices). A number were proud of the creative ways in which they managed to make 'things flow' across boundaries of the home, and of the kinds of networks they had created for the movement of their corporeal and representational selves. Faith, who had earlier described how her son and caregiver helped her to move mail and waste from her home, went on to to tell the interviewer how she is able to capitalise on visitors to her home for mediating relations to material objects and to make things move. She was pleased with her organisational skills, and her ability to exercise some power in organising and maintaining networks of people and things which enabled her to live alone.

Sounds like you've got things working well for you?

As well as I can. All I can do is organise. I organise everybody to an inch of their lives, if they show up. (Faith, 96)

Faith went on to tell the interviewer how she arranged people to call in and open tins for her in the morning or the night before - a practice necessary for her to make food flow. Participants had also developed strategies to enable 
forms of personal, financial and social mobility outside the home, which involved both people (setting up networks of friends and family to do banking, posting, using the phone and writing letters) and things (ranging from a device engineered to allow a participant to travel more easily in a private vehicle with a wheelchair, to using supermarket trolleys to rest on as a mobility aid).

In summary, 'getting out' was not always easy, particularly for the 12 elders who lived alone. While networks of neighbours, friends, family and social groups (such as churches, clubs) provided both possibility and opportunity to leave home for events, appointments and occasions, these networks were not always capitalised on. The existence of such networks (a type of stability and mooring that enabled the possibility of mobility) provided a form of security in the event of a necessities such as doctors' visits or getting groceries but appeared to be drawn on less often for 'getting out' for activities and interactions that participants perceived as merely desirable or that were deemed non-essential suggesting that mobilities are differentially evaluated. Utilising social networks also appeared to be a necessary part of how participants sought to enable flows of knowledge, material things and finances to spaces outside of the home (such as getting caregivers to take out rubbish or acquaintances to post mail). Ironically despite the desire to transcend home-space, one's motility (capacity to move both physically and imaginatively) was also impacted by the real and imagined experience of being in other spaces, and the known and predictable elements of socio-technical networks and their functioning providing a kind of mooring, but one predicated not so much on fixity in space but on the stability of the effective 'moving' parts and flows of wider material and social relations.

Alice's earlier sentiments about the recognition of the limits to her own corporeal mobility, and the ways in which this was compensated for through her friends coming into the home was a common sentiment expressed in interviews. In the face of both perceived and real impediments to 'getting out', participants discussed the ways in in which 'letting in' enabled them to establish connections with others and to achieve a sense of being in the world, a theme we explore in the next section.

\section{LETTING IN:}

A second way in which participants spoke about the movement of human and non-human things in their everyday life was with regard to the ways in which goods, services, knowledge, and information came into the home. The phrase 'letting in' was used to capture the way in which these flows were also associ- 
ated with notions of autonomy and control particularly over who and what moved across this space. A few participants talked about door-to-door sellers, and the need to defend their home boundary from entry by these salespeople. Tania had a clear idea of who she felt safe 'letting' into her house. For Tania, getting in someone to help with the housework was a desire and not a need, and consequently an area over which she was still able to exert some control:

There isn't a home service; I am appalled at the thought of getting one in. I've heard stories about theft.... If I knew where to get help. (Tania, 8o)

The 'letting in' with regard to human relations was often about trust, the management of insecurity, a predictability of knowing, and the power to enable or restrict movement across particular boundaries. Letting in, then, became a matter of territorial control for elders. Again, the movement of things into the house involved the enrolment of both human and non-human entities, thereby creating, drawing on, and stabilising connections with and to 'others'. For a number of elders 'letting in' was about the strategies they had developed which aligned with the workings of complex networks, so that they were able to capitalise on, or access flows of goods and services, for example, collecting daily deliveries of mail when one couldn't easily get to the letterbox. Nina jokingly tells the interviewer with regard to receiving mail:

No, all my friends are trained, they bring everything in! (Nina, 72)

Many of the older people consequently framed a sense of connectedness around notions of the mobility of the self (Zeigler \& Schwann, 2011), expressing the ways in which their mobility and sense of connectedness to the world extended beyond the limits imposed by their physical ability to move outside of the home.

A sense of mobility beyond the self was evident in the talk of participants who used a home-based library service (to have books in their area of interest delivered and collected from their door) or meals-on-wheels delivery services. Heather, for example, described how her physical impairment meant she could not do many of the things she used to do. For Heather, obtaining DvDs through the library service provided a form of mobility outside the limits of her body, providing a meaningful connection to others as her social world has closed in, but also sense of enjoyment, diversion and pleasure, enabling her to travel to other spaces without leaving home: 
I can't knit, I can't sew, I can't do embroidery, I can't do dress making. All the gardening, anything outside the house...I do cooking. I like cooking and that's really all that's left. But's that why we have DVDs from the library. (Heather, 88)

For other participants, junk mail, catalogue shopping, using the internet, listening to the radio and watching television also 'brought the world in', providing a sense of connectedness. This may fetishise home space and participants' relative immobility, but simultaneously expands notions of home and mobile practices, linking them to particular imaginaries of place (Bell \& Hollows, 2007). Catherine, wheelchair-bound, was asked how often she went shopping:

Oh spasmodic. I am helped a lot by junk mail which is one of the real advantages I find of junk mail if you are tied to the home the way I am. Gives you the chance to peruse them and spot things and go and get it you know. It's lovely. (Catherine, 75)

Catherine talks about the usefulness of junk-mail in browsing and making decisions in home space in bringing the retail world 'home', but simultaneously notes her purchase of it depends on 'going out' and on her own corporeal interactions in retail space - remaking her as a mobile Other (Jenson, 2010).

The analysis of transcripts surrounding the theme 'letting in' revealed that flows of people, ideas, images, practices and capital into homes was significant. For many home-based participants, 'letting in' provided a sense of autonomy and agency - a form of mooring, which enabled one to feel some control over the nature of services, visitors and information moving into the home, and over the maintenance and organisation of home territory. While, as mentioned previously, such narratives can be a reminder of one's relative immobility, disablement and disempowerment in relation to more mobile 'Others', letting in was also a medium for alternative forms of mobility (for example, a mobility of the self, expressed through the ability of books and DVDs to take one elsewhere). Thus discussion of letting in revealed that movements of human and non-human entities into one's home can alter the relationship between physical mobility and existential mobility (Hage, 2005) and help shape one's identity and place in the world. For one couple, ordering groceries from their local supermarket over the phone and having them delivered made them feel they were in relationship to the local store owner and that they were an acknowledged part of their local community. These possibilities and problems of doing mobility differently are at the heart of the third construct which emerged from the analysis, that of 'finding a way'. 
FINDING A WAY:

In telling stories of their interactions with organisations, participants alluded to challenges and opportunities facing them in 'finding a way' to access resources, communicate and be differently mobile. A number spoke about their determination to overcome such challenges. Many nevertheless reflected on the ways in which existing forms of technologies, transportation, communication and organisational practice did not easily accommodate their differing ablement and mobility. At times this was seen as embarrassing and worked to constrain participants' desire to go to these places or to enter into forms of interactions. This is exemplified in Dale's talk where she described her reluctance to go to restaurants, because she could not read the menus:

'Cause I've got to have it read out to me and that's embarrassing. (Dale, 75)

However despite recognising a dependence on others and on the functioning and flows of human and non-human things as part of networks of organisational and communicative practices for establishing mobile 'lives', participants were keen to establish a sense of identity and resilience which was not based around notions of mobility deficit. Accordingly, participants sought to refute negative renderings of themselves as immobile, still, inactive and abnormal that came from their inability to successfully negotiate interactions with organisations in predictable or prevailing ways. For example, Dale, whose sight was failing, is at pains here to describe the ways in which an electronic funds transfer at point of sale (EFTPOS) machine does not accommodate people who have 'normal' vision either:

Oh Yes, yes. A lot of EFTPos ones you can't use if the sun is shining on them. I don't think a normal person can, can they? (Dale, 75)

Participants actively endeavoured to adapt to 'life challenges' which enabled the maintenance of previously established roles and relations (Rowles, 1983). James, like many others, described how he accepted the physically disabling effects of his stroke, but intentionally sought to find solutions to the challenges he faced in everyday life:

And you know your limitations, like the chap next door; he's had the same sort of stroke and he is finding it difficult. I said to him you've got to learn to accept it and learn how to get round problems it gives you. (James, 74) 
Mobility practices as described by participants could include using others to make things flow in and across home space (as talked about in earlier sections), relying on assistive devices to enable bodies to overcome barriers to physical movement, or using existing technologies differently (such as using door frames or supermarket trolleys for weight bearing, resting or balancing). A number sought to purposively develop communicative networks (such as greater use of the phone or internet) in order to maintain their sense of having productive, active and contributing lives. That motion and emotion are kinaesthetically intertwined and produced together was evident in the ways which people expressed their frustration and pleasure when describing the conjunction of bodies, technologies and cultural practices as it applied to their own mobile practices (Sheller, 2004a:227). Nina, for example, recognised her organisation of chairs in the home was not conventional and felt she should justify their presence in strange places, but at the same time she talked with pride about the ways in which the specific arrangement of these mundane items, a kind of predictable mooring, enabled her to be independent and physically mobile within her home:

And I have chair in the hall and I have a chair in the kitchen so I can get from Point A to Point B and if I need to sit its (the chair) there, so that's why there's odd chairs in places round the place. (Nina, 72)

For a minority of participants - a 'connected' and engaged life was found not just through using mundane objects in ways that differed from their designed purpose or appropriate place, but through information technologies. Using the internet enabled a form of virtual mobility, a subjective sense of self and an autonomy of being that was not constrained by physical limitations or bounded by home space. Nina, who was studying for a university degree and who used Facebook and email, talked about the ways in which this enabled her not just to be connected to a whole range of organisations, but to make money, ideas, information, and consumer goods flow in and out of the house. Here she described the pleasure to be had from spending time on the computer and the way it had enabled her to interact with a whole range of organisations:

\section{What's your preferred way of dealing with these organisations?}

For me for everything - the computer is fantastic! I mean I'm computer literate. I've been on computers for 20 years.... I'm happier at home than out really, I've got my computer, I spend a lot of time on the computer and I'm perfectly happy doing that or reading. (Nina, 72) 
Thus communicative travel, whether by phone or internet, enabled older people to connect with friends and family, organisations and service providers, providing greater possibilities for elders to interact than corporeal travel might permit (Burnett \& Lucas, 2010).

However, participants also clearly recognised the limitations on their mobilities imposed not just by the material qualities of singular objects (such as an ATM, a price ticket with small writing, or a heavy door) but through a combination of social and material relations which define a particular network. Here Catherine talks about trying to access cash, and of the need to overcome a whole range of factors which comprise the social and spatial network in which flows of finances are produced to enable her to make money flow:

Oh yes, well, the bank, you see you can ring up... you can ring up Wellington. Say you need a new cheque book but you've got to have this huge number and of course I can't read it. I've got a machine there that magnifies things but by the time I poke the numbers, look at the thing and poke them, it, they cut me off and so, so I went, and so that's the most frustrating. So what happened in January, my brother marched me into the bank in town, and so I wanted to put some money in a, you know to give him a loan, and so the lady there that interviewed me about it, she said, I was telling her what a job I had trying to, cause you see you're supposed to be able to ring them and get money or put money in and I said I can't manage it. I said they get, they get frustrated at the other end... (Catherine, 73)

Catherine's ability to make money flow was caught up in her corporeal ability to get to an АTM (normally facilitated by family members and friend), her visual ablement, the capacity of the ATM to cope with this, her brother, the phone (which she was had difficulty in using), the frustrations of the phone bank operators, the policies and procedures and staff of the bank in town. Eventually she and the bank were able to work out a system for accessing money from home, but it required a different alignment and organisation of the socio-technical network, the intervention of a family member and an alternative bank practice.

The previous excepts have demonstrated the significance of the material world (e.g. machines, signs, furniture, built environments, technologies and implements) in facilitating and discouraging older people from doing mobility differently and finding a way to achieve their personal and practical goals in interacting with a range of organisations. The analysis revealed that 'getting out', 
'letting in', and 'finding a way' were not simply an accomplishment of the mind/ body. Rather as they recounted stories of their encounters with organisations they recognised the ways in which mobile practices were caught up in complex arrangements of people and things, some aspects of which they had limited ability to control or maintain. Regardless, 'finding a way' was a metaphor for the ways in which these elders sought to retain a sense of independence and autonomy and through which they sought both recognition and accommodation by organisations of the possibilities of being differently mobile.

\section{CONCLUSIONS OR INTERSECTIONS? MOBILITIES AS CONNECTION}

While it is important to recognise that older people generally, and the elders who volunteered as part of this study, do not comprise a homogenous group, their stories did highlight the ways in which experiences of interacting with organisations involved various forms of mobility. Participants' texts contained multiple accounts of the abilities of the self and organisations as part of wider socio-material networks to enable things, knowledges and peoples to move across spaces where their own bodies could not easily go. The movement of things, knowledges and people across the boundaries of the home were significant in the lives of home-based elders not just because they facilitated necessary material practices in everyday life such as getting food, buying clothes, paying bills and having contact with other humans. Rather for many elders successful interactions represented a means of mobility beyond the body, a way in which their presence was both represented, felt and had effect in spaces beyond the home. The stories of these older people reveal that being confined to domestic space does not necessarily involve living in a way removed from other social life (Williams, 1983). Mobile practices, be they corporeal or representational, provided a meaningful connection to significant others, localities and communities.

This research has demonstrated that immobility is not an inherent feature of the home based, nor of impaired or unwell bodies, but an outcome of many micro and macro relations between human and non-human entities. These 'more than human' relations comprise networks in which flows are both present and dependent on each other across multiple scales (from the circulation of neurons, cells, electricity, components and information which are involved in turning on a microwave button to the multiple flows and practices which enable booking a package holiday on computer). Our analysis revealed that even the most banal and simple things (e.g. a sign which cannot be read or an elevator button) can limit the capacities and desires of elders to move freely and to make things move (May, Garrett \& Ballantyne, 2010). In discussing 'get- 
ting out' we demonstrate the ways in which home-based elders might evaluate (and value) and prioritise forms of mobility (such as journeys in and out of home for practical versus pleasurable reasons) and highlight the need to further explore connections between motility versus mobility. Discussion around 'getting out' and 'letting in' also revealed the ways in which sociability is a critical part for many home-based elders of their existential mobility and connectedness, whether this involves encounters that take place within or outside the boundaries of home. An important dimension in accessing care or library books at home, having a phone conversation with a bank employee, or going into a shop is an ability to connect (albeit briefly in some cases) meaningfully and pleasurably with others, to feel comfortable and in control in the spaces they inhabit.

A recurrent theme which underpins all three thematic constructs, but particularly the notion of 'finding a way', is the need for home-based elders to have some sort of predictability and/or ability to organise the socio-technical networks which enable a mobility of self (such as making a phone call, relying on a caregiver or finding one's way around), a predictability that is dependent not necessarily on fixity in space, but on the stability of relations between people and things in time and space. The experience of this small group of home-based elders has revealed differently mobile people may actually mobilise things differently. Participants recognised that the predictability associated with functioning networks was often predicated on a lack of cognitive, social and physical impairment, a taken-for-grantedness many found frustrating. Ironically, ensuring predictability for those with differing mobility may come from the creation of socio-technical networks which allow greater flexibility. Excerpts from our final section on 'finding a way' highlight the need for organisational practices and socio-technical networks to accommodate such corporeal difference and the diverse possibilities older people have for being mobile. ${ }^{8}$

Through the case studies of getting out, letting in and finding a way, we have demonstrated how mobilities are dependent on complex and to some extent inseparable arrangements of both human and non-human things. In common with social disability models (Oliver, 1990) which recognise the ways in which society can intentionally or inadvertently promote social and spatial structures and negative attitudes which emplace people as 'old' or 'disabled', the study has revealed that participants' varying abilities to be mobile may be produced and represented differently with regard to the perceptions and actions of both self and others. Such attitudes can be enshrined in the networks of relationships which comprise the social and material world, revealing the ways in which the verbal and oral are privileged in the corporeal travel of bodies (Bissell 2009a; 
2009b). In this study, participants recognised the ways in which their sensory practices, experiences and knowledges differed from less impaired and more mobile others. Many acknowledged their relative exclusion from standardised means of engagement and connection such as face-to-face interactions outside of the home, automated phone answering systems, internet or phone bill payment or banking, using ATMs. Such recognition made visible the power enacted through the limited capacities of the socio-technical networks to accommodate them (Schillmeier 2007:598).

A view of mobility as connectedness rather than corporeal travel opens up possibilities for developing practices that accommodate the flows of people, things and knowledges across spaces and by multiple means (for example, by providing a range of means for accessing money, services, goods, organisations which are not predicated on face-to-face contact outside the home). The social model of disability (Oliver, 1990) also emphasises the changes required in society and the kinds of practical interventions necessary to empower those with physical and psychological impairments such as changing attitudes, improving social support, providing information, providing flexibility of structures, and altering built environments. However, in emphasising older peoples' mobility as more than human and more than physical, this paper specifically draws attentions to the capacity and properties of non-human entities in shaping mobilities. Consequently improving possibilities for mobile practices of older people must depend not only on recognising and changing the weight of signification and social understandings of immobility and ageing, but on acknowledging the interconnectedness of bodies and technologies, and the ways in which such entanglements may limit or enable possibilities for change (Bissell, 2010).

Thus achieving the 2001 Positive Ageing vision of 'a society where people can age positively, where older people are highly valued and where they are recognised as an integral part of families and communities' involves a recognition not only of how elder bodies move and sense, but the ways in which systems and organisations enable or disable people to live mobile lives, both within and beyond the confines of physical movement. If the problems of mobility for home-based elders are to become possibilities, this will require the determination of elders and organisations to 'find a way' but also attention to the arrangements of space and the kinds of practices which enable not only people, but also material things and knowledges to flow.

ACKNOWLEDGEMENTS

The authors would like to acknowledge our research team colleagues (Dr Mary 
Simpson, Dr Margaret Richardson, Dr Michael Cameron, and Professor Peggy Koopman-Boyden) and our research participants. We are grateful to the Foundation for Research Science and Technology which provided funding for this project (Contract UOWX0901,'Engaging Senior Stakeholders: Positive Ageing at the Organisation-Elder Interface'). Thanks also to the reviewers of this paper, and to Martha Bell as guest editor of this special issue, for their insightful comments and suggestions.

\section{NOTES}

1 https:/www.msd.govt.nz/what-we-can-do/seniorcitizens/positive-ageing/progress/goal-4.html

2 The authors recognise the challenge of settling on a positive term used to describe a wide diversity of older people. Following Minichiello, Browne and Kendig (2000) we use the word 'elder' as the general term for the population group over the age of 65 while simultaneously recognising the heterogeneous nature of this group and the nuances of the meanings of what it is to be chronologically older, and to feel 'old' and 'older' in society.

3 This paper deals with spatial mobility (Kellerman, 2011), which emphasises the movement of people and things (in both material and dematerialised forms) through space. This can be seen as distinct from 'social mobility' which emphasises socio-cultural mobility in terms of social stratification (such as an ability to transcend barriers of class), though in practice the social and spatial aspects of mobilities are interconnected. This paper examines the ways in which people are mobile through the routines and practices of everyday life, rather than reflecting mobilities in terms of migration (Blunt, 2007), moving home (de Groot, Mulder, Das \& Manting, 2011) or travelling as a way of life (Shubin, 2011).

4 See for example Levin's (2009) discussion of the diversity of older people's movement outdoors.

5 FRST was subsequently renamed the Ministry for Science and Innovation and at this writing is being restructured and renamed again.

6 The project team is Professor Theodore E. (Ted) Zorn (Massey University), Dr Mary Simpson (Waikato University), Dr Margaret Richardson (Waikato University), Dr Michael Cameron (Waikato University) and Professor Peggy KoopmanBoyden (Waikato University) and Dr Juliana Mansvelt (Massey University). 
7 By definition (in contrast to the home-based elders) these were elders who were able to leave home without assistance. The implicit and dichotomised notions of mobility and activity embedded in these initial research categorisations of active and inactive older people were demonstrated through the interview and observation log analyses to be problematic.

8 Phases II and III of the research are intended to develop age-friendly practices which accommodate the specific and varying needs of older people (including home-based elders) in consultation with participants and selected organisations. The outcomes of these phases are intended to build on the experiences of and analytical insights about the predictablity and flexibility of socio-technical networks created by differently mobile elders.

\section{REFERENCES}

Adey, P. 2010 Mobility. Abingdon and New York: Routledge.

Ayis, S. A., Bowling, A., Gooberman-Hill, R., and Ebrahim, S. $2007^{\text {'The effect }}$ of definitions of activities of daily living on estimates of changing ability among older people', International Journal of Rehabilitation Research, 30(1):39-46.

Babbie, E. 1998 The Practice of Social Research. Belmont: Wadsworth Publishing Company.

Banister, D., and Bowling, A. 2004 'Quality of life for the elderly: the transport dimension', Transport Policy, 11(2): 105-115.

Bell, D., and Hollows, J. 2007 'Mobile Homes', Space and Culture, 10(1):22-39.

Bissell, D. 2009a 'Visualising everyday geographies: practices of vision through travel-time', Transactions of the Institute of British Geographers, NS 34(1): 42-6o.

Bissell, D. 2009b 'Travelling vulnerabilities: mobile timespaces of quiescence', Cultural Geographies, 16(4): 427-445.

Bissell, D. 2010 'Vibrating materialities: mobility-body-technology relations', Area, 42(4):479-486. 
Blunt, A. 2007 'Cultural geographies of migration: mobility, transnationality and diaspora', Progress in Human Geography, 31(5):684-694.

Burnett, P., and Lucas, S. 2010 'Talking, walking, riding and driving: The mobilities of older adults', Journal of Transport Geography, 18(5):596-6o2.

Cresswell, T. 2010 'Towards a politics of mobility', Environment and Planning D: Society and Space, 28(1):17-31.

Dant, T. 2008 'The 'pragmatics' of material interaction', Journal of Consumer Culture, 8(1):11-33.

Davey, J.A. 2007 'Older people and transport: coping without a car', Ageing \& Society, 27(1): 49-65.

de Groot, C., Mulder, C.H., Das, M., and Manting, D. 2011 'Life events and the gap between intention to move and actual mobility', Environment and Planning A, 43(1):48-66.

Frello, B. 2008 'Towards a discursive analytics of movement: on the making and unmaking of movement as an object of knowledge', Mobilities, 3(1):25-50.

Graham, S., and Thrift, N. 2007 'Out of order: understanding repair and maintenance', Theory, Culture and Society, 24(3):1-25.

Hage, G. 2005 'A not so multi-sited ethnography of a not so imagined community', Anthropological Theory, 5(4):463-475.

Hannam, K., Sheller, M., and Urry, J. 2006 Editorial: 'Mobilities, Immobilities and Moorings', Mobilities, 1(1):1-22.

Jensen, O.B. 2010 'Negotiation in Motion: Unpacking a Geography of Mobility', Space and Culture, 13(4):389-402.

Katz, S. 1983 'Assessing self-maintenance: activities of daily living, mobility and instrumental activities of daily living', Journal of the American Geriatrics Society, 31(12): 721-727.

Kellerman, A. 2011 'Mobility or mobilities: Terrestrial, virtual and aerial categories or entities?' Journal of Transport Geography, 19(4):729-737. 
Latour, B. 2007 Reassembling the Social: An introduction to actor-network-theory. Oxford: Oxford University Press.

Laws, G. 1994 'Aging, contested meanings, and the built environment', Environment and Planning A, 26(11):1787-1802.

Levin, L. 2009 'Mobility in Later Life: Time, Choice, and Action'. In P. Vannini (ed.), The Culture of Alternative Mobilities. Farnham and Burlington: Ashgate: $141-158$

May, E., Garrett, R., and Ballantyne, A. 2010 'Being mobile: electric mobilityscooters and their use by older people', Ageing \& Society, 30(07):1219-1237.

Metz, D.H. 2000 'Mobility of older people and their quality of life', Transport Policy, $7(2): 149-152$.

Miles, M.B., and Huberman, A.M. 1994 Qualitative Data Analysis. Thousand Oaks: Sage.

Minichiello, V., Browne, J., and Kendig, H. 2000 'Perceptions and consequences of ageism: views of older people', Ageing \& Society, 20(03):253-278.

Mollaoğlu, M., Tuncay, F.Ö., and Fertelli, T.K. 2010 'Mobility disability and life satisfaction in elderly people', Archives of Gerontology and Geriatrics, 51: e115-e119.

Mollenkopf, H., Hieber, A., and Wahl, H.-W. 2011 'Continuity and change in older adults' perceptions of out-of-home mobility over ten years: a qualitativequantitative approach', Ageing \& Society, 31(5):782-802.

Oliver, M. 1990 The politics of disablement. London: Macmillan.

Patla, A.E., and Shumway-Cook, A. 1999 'Dimensions of mobility: defining the complexity and difficulty associated with community mobility', Journal of Aging and Physical Activity, 7(1):7-19.

Rowles, G.D. 1983 'Geographical dimensions of social support in rural Appalachia’, in G.D. Rowles and R.J. Ohta (eds), Aging and milieu: environmental perspectives on growing old. New York: Academic Press:111-13o.

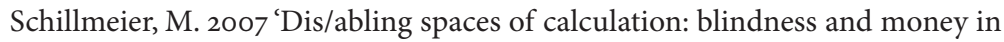


everyday life, Environment and Planning D: Society and Space, 25(4):594609.

Schwanen, T., and Ziegler, F. 2011 'Wellbeing, independence and mobility: an introduction'. [10.1017/So144686X10001467]. Ageing \& Society, 31(05):719-733.

Sheller, M. 2004 'Automotive emotions: feeling the car', Theory, Culture \& Society, $21(4 / 5): 221-242$.

Sheller, M., and Urry, J. 2006 'The new mobilities paradigm', Environment and Planning A, 38(2):207-227.

Shubin, S. 2011 'Travelling as being: understanding mobility amongst Scottish Gypsy Travellers', Environment and Planning A, 43(8):1930-1947.

Stalvey, B.T., Owsley, C., Sloane, M.E., and Ball, K. 1999 'The life space questionnaire. A measure of the extent of mobility in older adults', Journal of Applied Gerontology, 18(4): 460-478.

Urry, J. 2007 Mobilities. Cambridge: Polity Press.

Webber, S.C., Porter, M.M., and Menec, V.H. 2010 'Mobility in Older Adults: A Comprehensive Framework', The Gerontologist, 50(4):443-450.

Whatmore, S. 2006 Materialist returns: practising cultural geography in and for a more-than-human world, Cultural Geographies, 13(4):600-609.

Wiles, J. 2005 'Conceptualising the importance of place in the care of older people: the role of geographical gerontology', International Journal of Older People Nursing, 14(8b):100-108.

Williams, R. 1983 Towards 200o. London: Chatto \& Windus.

Ziegler, F., and Schwanen, T. 2011 "'I like to go out to be energised by different people": an exploratory analysis of mobility and wellbeing in later life'. [10.1017/ So144686X10000498]. Ageing \& Society, 31(5):758-781. 